\title{
ConTrole do USO do TABACO: NECESSIDADE SOCIAL E POSSIBILIDADE JURÍDICA
}

\section{Dalmo de Abreu Dallari*}

1. O consumo do tabaco e de seus derivados é um dos mais graves males que afetam o direito à saúde, que é um dos direitos fundamentais da pessoa, cuja proteção e efetivação é condição necessária para o gozo de muitos outros direitos, inclusive do direito à vida. Por essa razão, e tendo em conta que da disseminação do consumo do tabaco e do estímulo ao aumento do número de consumidores decorrem graves efeitos sociais, inclusive sobre pessoas que não são consumidoras diretas, mas que sofrem os efeitos do tabagismo, impõe-se o controle do tabaco. Isso é hoje universalmente reconhecido e já tem sido objeto de discussões e decisões em organismos internacionais, havendo, entretanto, muitas resistências a esse controle, originárias, sobretudo, da mobilização de interesses econômicos ligados ao tabaco. Para a superação dessas resistências e efetivação do controle do tabaco, foram celebrados tratados internacionais, merecendo especial atenção o fato de que o primeiro tratado global na área da saúde foi justamente a Convenção-Quadro para o Controle do Tabaco, aprovada pela Assembleia da Organização Mundial da Saúde (OMS) em 2003.

Esse é o tema central da presente edição da Revista de Direito Sanitário, estando aqui reunidos trabalhos elaborados por estudiosos e pesquisadores que trouxeram ricos e valiosos elementos informativos e procederam à análise de instrumentos jurídicos e decisões judiciais relacionados com o controle do tabaco, tanto no plano internacional quanto no Brasil, dando, assim, expressiva contribuição para o conhecimento do problema, de sua gravidade e amplitude. Como fica bem evidenciado por esses trabalhos, a questão do tabaco é relevante para diversas áreas do conhecimento, por todas as suas implicações.

Assim, por afetar direitos fundamentais e pela necessidade de medidas de repressão que irão repercutir sobre interesses econômicos de grande expressão,

(*) Professor emérito da Faculdade de Direito da Universidade de São Paulo.

Texto recebido em 19.01.13. 
o controle do tabaco é de muito interesse para o direito, mas também para a ciência econômica. Ao mesmo tempo, é de interesse mais do que óbvio para as ciências da saúde e apresenta grande relevância para a ciência política e para as disciplinas que tratam do governo e da administração pública. Alguns dados estatísticos deixam mais do que evidente a necessidade urgente de políticas públicas e medidas de governo que estabeleçam o efetivo controle do tabaco. Segundo dados da OMS, no ano de 2000, morreram em torno de cinco milhões de pessoas por causas ligadas ao tabaco, registrando-se que, em cada dez mortes, uma, pelo menos, foi devida ao tabaco. E a previsão é de que, se não forem adotadas severas medidas de controle, o número de mortes chegará a 30 milhões no ano de 2030.

Paralelamente, havendo já o reconhecimento de que a publicidade e as promoções têm papel-chave no estímulo ao consumo do tabaco, inclusive exercendo enorme influência para o induzimento ao consumo por crianças e adolescentes, essa é também uma área das atividades sociais que deve ser rigorosamente controlada e que, por isso, foi objeto de atentas considerações nos estudos aqui reunidos.

2. O exame de questões jurídicas relacionadas com o tabaco, sobretudo da crescente normatividade internacional relativa ao seu controle e da efetivação dessas normas, mas dando grande ênfase aos aspectos ligados à publicidade e à sua limitação por disposições jurídicas, é a temática central do trabalho intitulado Restrições à publicidade e promoção do tabaco e a liberdade de expressão. Conflito de direitos? Seus autores, Oscar Cabrera, Paula Avila Guillén e Juan Carballo, assinalam que na Convenção-Quadro, que é um tratado internacional, existem dispositivos expressos recomendando a adoção de políticas públicas de controle do tabaco, merecendo destaque a proibição da publicidade e da promoção de produtos do tabaco.

Ressaltados esses pontos, é dada ênfase especial a uma decisão recente da Corte Constitucional da Colômbia que muda substancialmente o enfoque dado à questão do controle nas decisões judiciais ocorridas até agora em diferentes tribunais, mostrando a possibilidade de um controle rigoroso sem ofensa às normas jurídicas de direitos fundamentais. Essa decisão é inovadora, pois, até agora, em nenhum caso chegado ao Judiciário havia ocorrido uma discussão ampla e uma aprofundada análise das alegações contrárias ao controle.

O ponto central da decisão da corte colombiana, e que muda radicalmente o enfoque do problema, é uma sólida fundamentação demonstrando que o controle da publicidade do tabaco vincula-se à questão da liberdade de comércio e não à liberdade de expressão, que é direito fundamental da pessoa. Essa diferenciação, como assinalam os autores desse trabalho, é de fundamental importância, pois abre a possibilidade de rigoroso controle, que pode chegar mesmo à proibição total da publicidade sem que se possa alegar ofensa à liberdade de expressão. Na realidade, o argumento segundo o qual as políticas 
de controle são ilegais, por contrariarem as normas de direito internacional que consagram o direito humano à liberdade de expressão, vem sendo sistematicamente invocado para acobertar as verdadeiras razões da oposição ao controle, que são, na realidade, ligadas ao interesse da liberdade de comércio. Aliás, é oportuno lembrar que muito recentemente os interesses comerciais impuseram limitações à exportação brasileira de carne para vários países, sob o falso pretexto de proteção à saúde de suas populações.

Um dado importante, assinalado pelos autores, é que, em casos anteriores que ensejaram decisões judiciais, nunca houve um exame aprofundado das alegações e de seus fundamentos para que se aceitasse a alegação de ofensa ao direito de livre expressão. Sempre se aceitou sem discussão esse argumento, estabelecendo-se, graças a isso, uma barreira judiciária para o controle do tabaco. Precisamente por isso a recente decisão da Corte Constitucional da Colômbia tem excepcional importância, pois não só ocorreu uma mudança de orientação, mas, o que é mais significativo e de maior importância, mudou-se o enfoque do problema, afastando-se a alegação de ilegalidade por ofensa ao direito à liberdade de expressão e deslocando a questão para o âmbito da liberdade de comércio.

É oportuno observar que a liberdade de comércio também é reconhecida como um direito, figurando em muitos atos jurídicos de expressão nacional e internacional. Na realidade, a liberdade de comércio é objeto de normatização internacional, que inclui tratados internacionais e acordos entre países e partes diretamente interessadas, para obstar medidas discriminatórias e protecionistas que impeçam a livre concorrência por imposições arbitrárias do poder econômico. Mas a questão do interesse na publicidade e promoção do tabaco se coloca no âmbito dos interesses comerciais, da liberdade de comércio, que não tem a importância e o significado da liberdade de expressão, que é direito fundamental da pessoa, de todas as pessoas, pelo reconhecimento universal de que tal liberdade faz parte das necessidades essenciais dos seres humanos.

Outro dado importante é que a própria Colômbia já havia dado um passo fundamental no sentido da implantação do controle efetivo do tabaco. Com efeito, por meio da Lei $\mathrm{n}^{\circ} 1.335$, de 2009 , foram estabelecidas rigorosas restrições à publicidade do tabaco naquele país. Por essa lei ficou proibido que nas etiquetas e embalagens se faça a sugestão de que fumar contribui para o sucesso atlético e esportivo, para a popularidade da pessoa, para o sucesso profissional ou melhor desempenho sexual. Além disso, ficou expressamente proibida a publicidade enganosa, que procura disfarçar a agressividade do tabaco na apresentação e oferta dos produtos, mediante o uso de expressões como "suaves", "leves", " doces", "de baixo teor em alcatrão, nicotina e monóxido de carbono". Além disso, a lei exige que nas embalagens sejam claramente inseridas frases de advertência quanto aos riscos do consumo de tabaco para a saúde da pessoa.

Foi numa tentativa de reação a essas disposições legais de controle que a matéria chegou à Corte Constitucional, ensejando a importante decisão 
inovadora, que por sua sólida fundamentação jurídica deverá consagrar-se como um marco jurisprudencial. E a divulgação dessa decisão em outros países deverá contribuir para que se generalize a nova orientação, não só influindo para a mudança jurisprudencial, mas também encorajando e estimulando a adoção de medidas, como a legislação e a implantação de políticas públicas, para a efetivação das restrições à publicidade e promoção do tabaco, sem que se possa alegar ofensa à liberdade de expressão.

3. O trabalho a respeito da influência do direito internacional na legislação interna sobre o controle do tabaco analisa, com base em informações oportunas e precisas, a normatividade internacional relativa ao controle do tabaco e seu relacionamento com o sistema normativo e administrativo brasileiro. Aqui também é dada grande ênfase à Convenção-Quadro para o Controle do Tabaco, aprovada pela Organização Mundial da Saúde em 2003 e incorporada ao sistema jurídico-normativo brasileiro em 2005. Além desse tratado, são ainda analisados outros dispositivos internacionais aplicáveis ao controle, ressaltando-se a possibilidade de efetivação das normas restritivas à publicidade e promoção do tabaco pelos órgãos que no sistema brasileiro são responsáveis pela saúde.

São esses os pontos essenciais do trabalho intitulado, precisamente, $O$ papel do direito internacional na legislação interna sobre o controle do tabaco, de cuja elaboração participaram Luís Renato Vedovato, Tatiana Giovanelli Vedovato e Ana Maria Girotti Sperandio.

Também nesse trabalho é dada especial atenção à Convenção-Quadro para o Controle do Tabaco da OMS, porém a partir de uma perspectiva mais ampla, observando que vem ocorrendo um grande avanço do direito internacional em termos de influência sobre as decisões e o desempenho dos Estados. Tendo em conta esse avanço, desenvolvem-se considerações sobre a necessidade do estabelecimento de normas jurídicas internas, em cada Estado, para dar efetividade às normas da Convenção. Para a consecução desse objetivo é necessária a definição e implantação de políticas públicas, as quais devem ser estabelecidas e postas em prática, tendo em conta as normas internacionais e em coordenação com elas, para que se busque a concretização dos objetivos definidos no plano internacional.

Acrescentando um dado importante para o exame dos aspectos jurídicos do controle do tabaco, os autores observam que, em sequência à Convenção-Quadro, foi estabelecida uma espécie de regulamentação internacional, numa perspectiva que se pode denominar de direito administrativo internacional. Para efetivação dos preceitos da Convenção e com base nesta, foram estabelecidas diretrizes práticas por meio de Conferências das Partes (COPs). Estas, que podem ser consideradas uma espécie de " braço executivo" de um acordo internacional, são encontros anuais reunindo representantes dos participantes do acordo, para conhecimento e avaliação da situação em que se encontra a busca de implementação do acordo, que no caso do tabaco é a Convenção-Quadro 
para o Controle do Tabaco. As Conferências das Partes estabelecem diretrizes que são obrigatórias para todos os participantes da Convenção e que fornecem base jurídica para a regulamentação interna dos Estados.

Desse modo, o governo e a Administração Pública dos Estados têm base jurídica para a fixação de normas, o estabelecimento de políticas públicas e a adoção de medidas concretas, impondo limitações e efetivando o controle do tabaco, inclusive da publicidade e das promoções. Assim, órgãos internos, como a Agência Nacional de Vigilância Sanitária (Anvisa), no Brasil, poderão e deverão mesmo dar aplicação prática àquelas diretrizes. Além de outras medidas de controle, poderá ser concretizado o que dispõem os arts. $9^{\circ}$ e $10^{\circ}$ da Convenção-Quadro, onde se estabelecem expressivas limitações ao tabaco. Entre estas figura, por exemplo, a limitação ao emprego de sabores nos produtos do tabaco, artifício usado e enfatizado na publicidade para atrair consumidores.

Reiterando a argumentação dos demais estudiosos do tema, aqui também se dá grande ênfase à recente decisão da Corte Constitucional da Colômbia, que mudou radicalmente o foco do problema, fazendo clara distinção entre a liberdade de expressão, como direito humano fundamental, e a liberdade de comércio, que também interessa ao direito, mas que se coloca noutra dimensão. A conclusão é que não existe conflito entre a livre iniciativa como direito individual, aí compreendida também a liberdade de expressão, e as restrições à publicidade do tabaco. Esta, segundo concluem, é parte da atividade econômica, é simplesmente um mercado, que pode ser tolerado, observados os limites impostos pela regulamentação, mas que não deve ser incentivada.

4. O outro trabalho constante desta edição da Revista de Direito Sanitário, que tem como tema central o tabaco, enfoca o estudo do problema na Colômbia, dando maior ênfase a um aspecto particular, que é a avaliação das etiquetas e embalagens dos produtos do tabaco. A autora, a colombiana Lorena Viviana Calderón Pinzón, exerce função pública no Ministério da Saúde e Proteção Social da Colômbia, o que lhe dá a possibilidade de conhecimento prático dos problemas de saúde.

Obviamente, a autora está bem informada sobre a legislação colombiana relativa ao tabaco e sobre os problemas práticos para sua efetivação, assim como, tem pleno conhecimento da decisão recente da Corte Constitucional da Colômbia, já aqui referida com pormenores, deslocando a problemática da publicidade do tabaco do campo do direito à liberdade de expressão para o campo da liberdade de comércio, abrindo, dessa forma, ampla possibilidade de controle pelo estabelecimento de restrições jurídicas e pela adoção de políticas públicas.

Certamente influenciada pelo conhecimento da situação concreta e pela verificação dos obstáculos opostos à implementação das regras regulamentadoras em vários setores e em diversos momentos do processo de comercialização do tabaco, a autora do presente trabalho elegeu como tema central de sua investigação aquilo que figura como título do artigo, ou seja, dedicou-se 
a fazer a Avaliação das Etiquetas e Embalagens de Produtos de Tabaco na Colômbia, propondo-se a estudar os principais desafios jurídicos no processo de implementação das medidas restritivas.

O ponto de partida jurídico para o comentário sobre os obstáculos opostos à efetivação das medidas de controle foi, obviamente, a Convenção-Quadro para o Controle do Tabaco da OMS. Na Convenção existem, efetivamente, disposições expressas e específicas sobre as etiquetas e embalagens dos produtos de tabaco, que são, na sua essência, as seguintes:

Art. 11 - Emabalagem e etiquetagem de produtos de tabaco.

Cada Parte, em um período de três anos a partir da entrada em vigor da Convenção para essa Parte, adotará e implementará (...) medidas efetivas para garantir que:

(a) a embalagem e a etiquetagem dos produtos de tabaco não promovam produto de tabaco de qualquer forma que seja falsa, equivocada ou enganosa, ou que possa induzir ao erro, com respeito a suas características, efeitos para a saúde, (...) incluindo termos ou expressões, elementos descritivos, marcas de fábrica ou de comércio, sinais figurativos ou de outra classe que tenham o efeito, direto ou indireto, de criar a falsa impressão de que um determinado produto de tabaco é menos nocivo que outros. (...)

(b) cada carteira unitária e pacote de produtos de tabaco, e cada embalagem externa e etiquetagem de tais produtos também contenham advertências descrevendo os efeitos nocivos do consumo do tabaco. (...)

2. Cada carteira unitária e pacote de produtos de tabaco, e cada embalagem externa e etiquetagem de tais produtos deverá conter, além das advertências especificadas no parágrafo 1(b) do presente Artigo, informações sobre os componentes e as emissões relevantes dos produtos de tabaco. (...)

3. Cada Parte exigirá que as advertências e a informação especificada nos parágrafos 1(b) e 2 do presente artigo figurem (...) em seu idioma, ou em seus principais idiomas.

Como fica evidente, a Convenção trata especificamente de pormenores das embalagens, estabelecendo exigências que deverão ser postas em prática nos países que aderiram ao documento, fazendo parte, portanto, das obrigações jurídicas assumidas por eles. Mas, além de considerar esse aspecto, a autora do artigo ora referido dá grande ênfase a outro instrumento jurídico internacional, geralmente identificado como Mpower. Esse documento é, essencialmente, um plano de ação, um plano de políticas públicas, estabelecido pela OMS em 2008, enumerando medidas de ordem prática que deverão ser adotadas para fazer retroceder a epidemia de tabagismo. O Mpower especifica seis providências básicas que deverão ser postas em prática, a saber: 1) monitorar o uso do tabaco e as políticas preventivas; 2) proteger as pessoas da fumaça do tabaco; 3) oferecer ajuda para que as pessoas deixem o tabaco; 4) advertir sobre os perigos do uso do tabaco; 5) dar efeito prático às advertências sobre a promoção e o patrocínio do tabaco; 6) aumentar os impostos sobre o tabaco. 
Ressaltando esses aspectos jurídicos e administrativos relacionados ao controle do tabaco, a autora lembra a necessidade de harmonização do conteúdo das disposições internacionais com a legislação interna dos Estados, enfatizando esse aspecto em relação à Colômbia, objeto imediato de seus estudos e pesquisas, bem como de suas atividades profissionais, na condição de funcionária do Ministério da Saúde e Proteção Social daquele país. Quanto a esse ponto, merece especial atenção uma lei colombiana, a Lei $n^{\circ} 1.335$, de 2009, já referida, que tratou especificamente do assunto. Esses dispositivos legais, que tiveram por objetivo inserir na legislação interna as disposições constantes de instrumentos internacionais como a Convenção-Quadro para o Controle do Tabaco, as decisões das Conferências das Partes e o Mpower, certamente influíram para que a Corte Constitucional proferisse a importante decisão em que fez clara distinção entre a liberdade de expressão e o livre comércio, afirmando a compatibilidade jurídica das disposições legais e administrativas internas com as normas internacionais que consagram e garantem os direitos humanos.

Todos esses elementos foram considerados na elaboração do trabalho sobre os desafios jurídicos para a implantação das normas internacionais e internas relativas às etiquetas e embalagens dos produtos do tabaco. Esse é um aspecto particular do controle do tabaco e que tem, como outros, grande importância prática, influindo para a eficácia das medidas de prevenção e das mensagens de advertência. Como bem reconhece a autora desse estudo, as exigências sobre peculiaridades das etiquetas e embalagens fazem parte de um conjunto muito amplo de medidas que se fazem necessárias e urgentes para buscar a redução do consumo do tabaco e de seus efeitos nefastos sobre a saúde da população.

5. O conjunto de trabalhos aqui reunidos deixa muito evidentes a importância e atualidade dos estudos e pesquisas relacionados ao consumo do tabaco. Existem efeitos diretos sobre os consumidores, mas também são muito graves os efeitos indiretos, que atingem pessoas que, embora não sendo fumantes, são forçadas a receber em seu organismo a fumaça do tabaco consumido, tendo-se, desse modo, um alto contingente de " fumantes indiretos" ou " fumantes passivos", que podem estar em qualquer ambiente social, sejam os locais de acontecimentos sociais, de reuniões e de práticas esportivas, como também os ambientes de trabalho e as escolas.

Entre outras ações de grande importância é destacada a necessidade de medidas de ordem econômica, entre as quais a exigência de preço elevado para a comercialização dos produtos do tabaco e uma alta imposição tributária sobre esses produtos. Mas, a par disso, como foi exposto nos trabalhos aqui reunidos e tem sido objeto da fixação de normas de controle em instrumentos jurídicos internacionais, são igualmente relevantes as limitações situadas fora do âmbito estritamente econômico. Entre estas vem sendo dada grande ênfase à proibição da publicidade, da promoção e do patrocínio de produtos do tabaco, em todas as suas expressões, pois muitos reconhecem que esse aspecto é 
fundamental para buscar a redução do número de consumidores, inclusive para que não haja o induzimento de crianças e adolescentes. Tudo isso é essencial e urgente para a contenção e redução do altíssimo nível de mortalidade humana decorrente, direta ou indiretamente, do uso do tabaco.

Por todos esses motivos, é necessária e oportuna a divulgação dos estudos e pesquisas sobre o tabaco e seus males, para conhecimento e estímulo de todos os que atuam em diferentes áreas de atividades, como o direito, a saúde, a educação, bem como aqueles que atuam nos poderes Legislativo e Judiciário e em todos os setores do governo e da administração pública, responsáveis pela proteção e promoção do desenvolvimento humano e dos direitos fundamentais da pessoa. 